\title{
High expression of estrogen receptor alpha and aromatase in glial tumor cells is associated with gender-independent survival benefits in glioblastoma patients
}

\author{
Lisa Stefanie Hönikl ${ }^{1,2} \cdot$ Friederike Lämmer $^{1} \cdot$ Jens Gempt $^{2} \cdot$ Bernhard Meyer $^{2} \cdot$ Jürgen Schlegel $^{1} \cdot$ Claire Delbridge $^{1}$
}

Received: 6 January 2020 / Accepted: 20 March 2020 / Published online: 2 April 2020

(c) The Author(s) 2020

\begin{abstract}
Introduction Glioblastoma multiforme (GBM) is a highly malignant glial tumor, affecting men more often than women. The reason for this gender-specific predominance remains unclear, raising the question whether these effects are subject to hormonal control. The purpose of this study was to examine the expression of estrogen receptor alpha (ER $\alpha)$ and aromatase in human GBM tissue samples in relation to patient survival and furthermore to investigate the effect of standard chemotherapy in combination with estradiol treatment on glioblastoma tumor cell lines in vitro.

Methods 60 tissue samples (31 male, 29 female) of GBM patients were analysed with immunohistochemistry for ER $\alpha$ and aromatase for survival analyses. The cell lines LN18 and LN229 were treated with 17ß-estradiol (E2) in different dosing regimens and the cell viability was measured with MTT assay. After estradiol pre-treatment Temozolomide was added and tested again.

Results High expression of ER $\alpha$ and aromatase in the GBM tissue samples was associated with significantly longer survival times of GBM patients, regardless of gender and body-mass-index. The treatment with high concentrations of estradiol resulted in lower tumor cell viability, compared to control. The cells significantly showed a stronger sensitivity against Temozolomid (TMZ) after estradiol pre-treatment.

Conclusion ER $\alpha$-expression of glial tumour cells seems to play an important prognostic role as a biomarker in GBM, as well as the expression of the enzyme Aromatase. The combined treatment of GBM with standard chemotherapy and estradiol may be beneficial to patient's survival.
\end{abstract}

Keywords Glioblastoma multiforme $\cdot$ Estrogen receptor alpha $\cdot$ Aromatase $\cdot 17 \beta$-estradiol $\cdot$ Survival $\cdot$ TMZ $\cdot$ Combined therapy in vitro

\section{Introduction}

Glioblastoma multiforme (GBM, WHO grade IV) is the most common and most malignant primary brain tumor in adults [1]. Despite maximal standard therapy [2] the

Lisa Stefanie Hönikl

lisa.hoenikl@tum.de

Friederike Lämmer

friederike.laemmer@t-online.de

Jens Gempt

jens.gempt@tum.de

Bernhard Meyer

bernhard.meyer@tum.de

Jürgen Schlegel

schlegel@tum.de prognosis is still poor and leads to a median overall survival of 15 months [3]. The incidence of GBM in the USA was 3.2/100,000 person years in 2015 and men are affected 1.6 times more often than women [4]. The reason for this gender-specific predominance still is unclear.

Claire Delbridge

c.delbridge@tum.de

1 Department of Neuropathology, Klinikum rechts der Isar, School of Medicine, Technical University of Munich, Munich, Germany

2 Department of Neurosurgery, Klinikum rechts der Isar, School of Medicine, Technical University of Munich, Munich, Germany 
Many neurological diseases like traumatic brain injury [5], stroke [6] and chronic progressive course [7] also show gender differences, which are most likely attributed to the neurobiology of reactive astrocytes and the expression of estrogen, estrogen receptors (ER) and aromatase. In traumatic brain injury female rats showed smaller tissue damages compared to male and ovariectomized female rats [8]. Female homozygous aromatase knock-out mice showed larger ischemic damage after reversible cerebral artery occlusion than the wild-type littermates, suggesting that the enzyme plays a key role in neuroprotective functions [9]. The neuroprotective functions of sexual steroid hormones are mainly mediated through ERs in astrocytes [10]. When GBM cells were transplanted into athymic mice [11] or nude rats [12] the tumor growth was higher in male than female animals, indicating that sexual hormones have a decisive influence on tumor proliferation.

Aromatase converts testosterone to estradiol as last step of estrogen biosynthesis. The enzyme, located in the endoplasmic reticulum, is expressed in the gonads, glial cells, neurons and the adipose tissue [13]. The main site of synthesis under physiological conditions in the brain are neurons, but there is also notable expression in glial cells [14]. Under pathological conditions the production shifts to glial cells, mainly astrocytes $[15,16]$.

Estradiol is a steroid hormone, synthesized from cholesterol in different organs: the gonads, the adrenals, the placenta and the brain. In the brain estrogen levels depend on the synthesis of estrogens by neurons and glial cells de novo but also on the absorption of blood derived estrogens $[17,18]$. Estrogen, as a steroid hormone, acts directly by binding nuclear ERs and initiates gene expression under physiological and pathological conditions [15]. There are two isoforms of estrogen receptors: $\alpha$ and $\beta$. Differences in ER subtypes suggest diverse function and tumor suppressive properties. Both receptors are expressed under physiological conditions and are lost or reduced during tumor development, indicating a potential tumor suppressive function [19]. Studies concerning cerebral ischemia show that neuroprotective effects are mediated by ER $\alpha$ and not $\operatorname{ER} \beta$, because the neuroprotection through estrogen is dependent on the presence of ER $\alpha$ [20,21].

The aim of this study was to evaluate the expression of ER $\alpha$ and aromatase in tissue samples of glioblastoma patients and to have a closer look at the reaction of glioblastoma cell lines to a combined therapy with estrogen and Temozolomid (TMZ).

\section{Materials and methods}

\section{Immunohistochemistry}

GBM tissue samples were surgically removed, formalin fixed, paraffin embedded and diagnosed as glioblastoma, IDH-wildtype (WHO grade IV), by two independent neuropathologists at our Department of Neuropathology.

Paraffin embedded tumor tissue was cut and placed on microscope slides. After deparaffinising and boiling in $10 \mathrm{mM}$ citrate buffer for $30 \mathrm{~min}$, the endogenous peroxidase was quenched in $1.5 \% \mathrm{H}_{2} \mathrm{O}_{2}$ for $10 \mathrm{~min}$. Avidin/Biotin Blocking Kit (Vector Laboratories Inc.) diluted in blocking buffer (PBS plus 1\% BSA, 0.1\% Trixon 100, 0.2\% Gold Fish Gelatine, $0.02 \%$ NA acid, $2.5 \%$ normal horse serum) was used for $30 \mathrm{~min}$. After washing in PBS the sections were incubated with an ER $\alpha$ antibody (DCS Innovative Diagnostik-Systeme $\mathrm{GmbH}, 1: 20$, clone $6 \mathrm{~F} 11$ ) or an aromatase antibody (Sigma-Aldrich Co., 1:150, clone 19A1) diluted in blocking buffer overnight at $4{ }^{\circ} \mathrm{C}$. The slides were washed in PBS and incubated with the secondary antibody for $30 \mathrm{~min}$ at room temperature (RT). After washing in PBS and incubation with Vecastan ABC Kit (Vector Laboratories Inc.) for 30 min at RT, ImmPACT DAB (Vector Laboratories Inc.) was used for developing under visual control. Counterstaining was done with Meyer's Haematoxylin and mounted with Pertex. Placenta and breast tissue were used as positive controls. For negative controls the first antibody was omitted.

The slides were quantitatively assessed (10 fields of vision in 20 fold magnification) and scaled in four staining groups: $1=0-10 \%, 2=11-40 \%, 3=41-70 \%, 4=71-100 \%$ of immune positive glial tumor cells in the vital tumor spreading regions. The Aromatase immunohistochemistry showed a distinct staining of the cytoplasm of glial tumor cells, which were rated as positive. The used ER antibody stains the alpha subtype. The glial tumor cells showed ER $\alpha$ positive cell nuclei, but also cytoplasmic expression of ERs $[15,22]$. For the assessment a tumor cell was rated positive when the cell nuclei alone or combined with the cytoplasm was positively stained.

\section{Cell culture}

GBM cell lines LN229 and LN18 were obtained from the American Type Culture Collection and cultivated in $75 \mathrm{~cm}^{2}$ flasks in a humidified 5\% $\mathrm{CO}_{2} / 95 \%$ air incubator in high glucose DMEM supplemented with 5\% fetal calf serum and $1 \%$ L-Glutamine at $37{ }^{\circ} \mathrm{C}$. 


\section{MTT assay}

Cell numbers were investigated using MTT assay. Briefly, cells were seeded in 96 well plates in $100 \mu$ medium. After finishing the experiment $10 \mu \mathrm{l}$ of the MTT labelling reagent (Sigma-Aldrich Co.) was added and incubated for $4 \mathrm{~h}$ in a humidified atmosphere. Then the medium was aspirated and $100 \mu$ of the solubilisation solution DMSO was added and incubated for 30 min shaking at RT. After the incubation period a spectrophotometrically absorbance measurement was done at $595 \mathrm{~nm}$ ( $650 \mathrm{~nm}$ reference wavelength). As control a triplet of wells per plate was treated under experimental conditions without any cells.

\section{Western blot}

GBM cell lines LN18 and LN229 were analysed for ER $\alpha$ protein. As positive control Gibco®Human Astrocytes (Life Technologies Corp.) were used, which express ER $\alpha$ under physiological conditions [15]. Cells were lysed in RIPA buffer (10 mM HEPES, $150 \mathrm{mM} \mathrm{NaCl}, 2$ mM EDTA, $1 \%$ NP 40, $1 \%$ Trixon and $10 \mu \mathrm{l} / \mathrm{ml}$ RIPA PMSF, $10 \mu \mathrm{l} / \mathrm{ml}$ RIPA proteinase-phosphatase-inhibitor), transferred to an Eppendorf tube, sonicated for $30 \mathrm{~s}$, incubated on ice for $15 \mathrm{~min}$ and centrifuged at $14,000 \mathrm{U} / \mathrm{min}$ for $10 \mathrm{~min}$ at $4{ }^{\circ} \mathrm{C}$. The resulting supernate was used for the Bradford calculation and the other part was diluted 5:1 in Lämmli-buffer [10\% SDS, $125 \mathrm{mM}$ Tris, 10\% Glycerol, 0.2\% Bromophenol solution, $250 \mathrm{mM}$ DTT (fresh added)], boiled for $5 \mathrm{~min}$ and electrophoresed on a 10\% SDS-PAGE gel. The protein transfer to the nitrocellulose membrane was done as a gel sandwich inside a tray in a transfer tank filled with transfer buffer at $4{ }^{\circ} \mathrm{C}$ for $1 \mathrm{~h}$ with $100 \mathrm{~V}$. The membrane was rinsed in TBS with $0.1 \%$ Tween 20 (TBST), blocked in 5\% bovine serum albumin in TBST for $1 \mathrm{~h}$ at RT and incubated with ER $\alpha$ antibody (6F11, Thermo Fisher Scientific Inc., 1:500) at $4{ }^{\circ} \mathrm{C}$ overnight. After several rinses in TBST, the membranes got incubated with HRP-linked horse anti-mouse antibody (1:5000 in 5\% BSA diluted in TBST) for $45 \mathrm{~min}$ at RT. Incubation with the HRP substrate (Merck KGaA) was performed after washing with TBST. After exposure of a film to the HRP wetted membrane the bands were visualized. Vinculin was used for the loading control.

\section{E2 and TMZ therapy}

Cells were seeded into a 96 well plate and treated $24 \mathrm{~h}$ later with estradiol (17 $\beta$-estradiol: E8875, Sigma-Aldrich Co.) in three different dosing regimens: $10 \mu \mathrm{M}, 25 \mu \mathrm{M}$ and $50 \mu \mathrm{M}$ diluted as described in the data information. After $48 \mathrm{~h}$ of incubation the cell viability was measured with MTT assay. After the estradiol treatment TMZ (SigmaAldrich Co.) was added in five different concentrations:
$25 \mu \mathrm{M}, 50 \mu \mathrm{M}, 100 \mu \mathrm{M}, 200 \mu \mathrm{M}, 400 \mu \mathrm{M}$ for 5 days and tested with MTT assay.

\section{Statistical analysis}

Excel 2016 and SPSS statistics 24 were used for all statistical analysis. Survival analysis was plotted on Kaplan-Meier curves according to the REMARK guidelines [23], adjusted to sex and body-mass-index. The Mantel-Cox lag rank test was used to compare survival distributions.

\section{Results}

\section{GBM cohort analysis of ERa and aromatase}

The GBM tissue samples, assessed as described in Materials/Methods and scaled in four groups: $1=0-10 \%$, $2=11-40 \%, 3=41-70 \%, 4=71-100 \%$ of immune positive glial tumor cells. The classification resulted from the fact that many tissue samples showed no or only a small amount of ER $\alpha$-positive stained tumor cells. Thus a clearer differentiation between less stained tissue samples was possible. For further classifications $0-40 \%$ (group 1 and 2) of immune positive stained tumor cells was rated as low expression of the hormones and $41-100 \%$ was classified as high expression.

Examples for each group of immunohistochemically stained tissue samples for ER $\alpha$ and aromatase as well as hematoxylin eosin are illustrated in Figs. 1 and 2.

The analysis of ER $\alpha$ staining demonstrated that 22 GBM tissue samples (12 female and 10 male) showed less than $10 \%$ immune positive tumor cells. Staining group 2 consisted of 20 tissue samples ( 8 female, 12 male) with $11-40 \%$ immune positive tumor cells. 13 tissue samples ( 5 female, 8 male) showed $41-70 \%$ of ER $\alpha$ immune positive tumor cells. 5 tissue samples demonstrated more than $70 \%$ of immunoreactive tumor cells, consisting of 4 female and 1 male patients.

The evaluation of the enzyme aromatase showed 2 tissue samples ( 2 female) with less than $10 \%$ of immune positive tumor cells. 8 GBM tissue samples, consisting of 4 female and 4 male patients, demonstrated $11-40 \%$ of immunoreactive cytoplasm. The staining group 3 consisted of 11 GBM tissue samples ( 8 female, 3 male) and 39 tissue samples showed more than $70 \%$ of immoreactive positive tumor cells (15 female, 24 male). 
Fig. 1 a ER $\alpha$ staining of GBM patients in each category $(\times 20)$. Picture a represents group $1(0-10 \%)$, b is group $2(11-40 \%)$, c group 3 $(41-70 \%)$ and $\mathbf{d}$ is group $4(71-100 \%)$. In picture $\mathbf{e}$ the hematoxylin eosin stainging is shown

\section{GBM patient characteristics}

The GBM cohort of the present study consisted of 60 patients ( 29 female, 31 male), with an age range from 25 to 85 years and an median age of 60 years for female and 58 years for male patients. The survival time of GBM patients after surgery ranged from 22 to 1920 days, with a median survival time for females of 411 days and male patients of 432 days. The patients received cross total resections followed by Stupp protocol consisting of radiation and chemotherapy. The patients had a Karnofsky index greater than $60 \%$. MGMT status is known for 57 of 60 patients. 29 patients have no methylation of the MGMT and 28 patients present a methylation. There is no statistically significant correlation between the expression of ERalpha or Aromatase and the MGMT status.

\section{Survival analysis regarding ERa and Aromatase}

For survival analysis the staining intentions were judged as low expression with lower $40 \%$ of immune positive tumor cells (staining group $1+2$ ) and high expression consisting of tissue samples with higher $40 \%$ of immune positive tumor cells (staining group $3+4$ ). The Kaplan-Meier analysis showed that high ER $\alpha$ expression (>40\% immunoreactive tumor cells) in GBM patients was associated with significantly longer survival (Log rank: $p=0.0111$, Fig. $3 \mathrm{a}$ ), compared to low expression of ER $\alpha$. Patients in the staining groups $3+4$ showed a median survival of 492 days, whereas patients rated in staining groups $1+2$ of ER $\alpha$ lived 371 days on median. GBM patients in high ER $\alpha$ staining groups lived 121 days on median longer than patients rated in staining group $1+2$. The same effect was seen in GBM patients with high aromatase expression ( $>40 \%$ immunoreactive tumor cells, Log rank: $p=0.0104$, Fig. $3 b$ ), compared to low expression of the enzyme. GBM patients with low expression of aromatase lived 236 days on median, compared to high expression with a median survival time of 444 days, which was a difference of 208 days. No gender difference in the survival of female and male GBM patients appeared (Log rank: $p=0.89$, Fig. $3 c$ ). The median survival time for female patients was 411 days and for male 432 days. Kaplan-Meier analyses were performed under adjusting to sex and BMI.

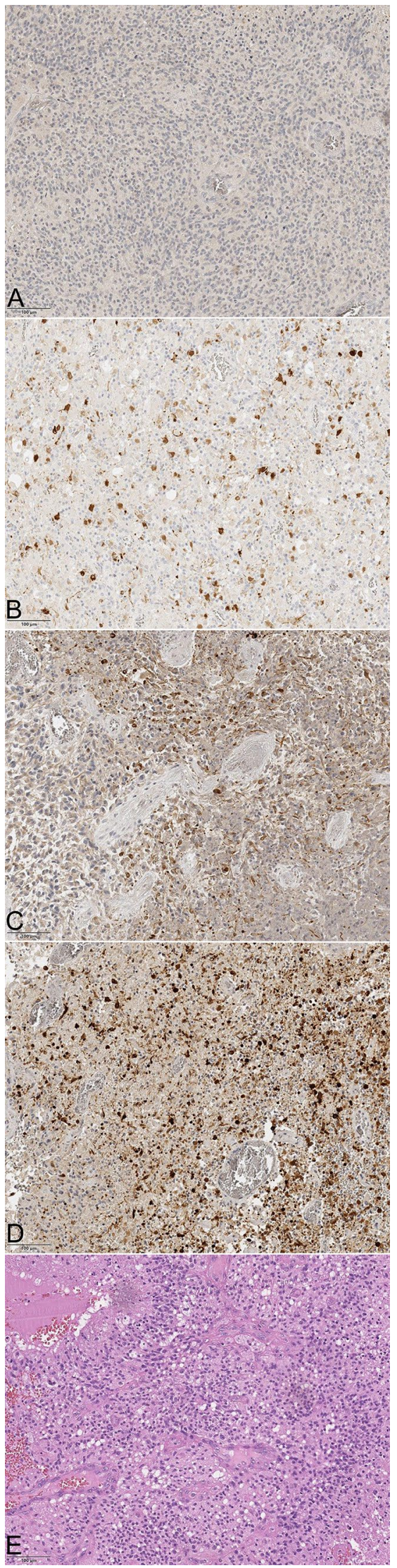


Fig. 2 a Aromatase staining of GBM patients in each category $(\times$ $20)$. Picture a represents group $1(0-10 \%)$, b is group $2(11-40 \%)$, c group $3(41-70 \%)$ and $\mathbf{d}$ is group $4(71-100 \%)$. In picture e the hematoxylin eosin stainging is shown

\section{Combined estradiol and TMZ therapy on GBM cell lines}

Before estradiol treatment a Western blot analysis was done, which confirmed that both cell lines LN18 and LN229 express ER $\alpha$ (Fig. 4).

Calculation of the half maximal inhibitory concentration $\left(\mathrm{IC}_{50}\right)$ of estrogen and TMZ was performed after therapy with estradiol alone and after the combined estradiol and TMZ treatment.

High concentrations of estradiol resulted in significantly lower tumor cell viability, compared to control (Fig. 5a). The $\mathrm{IC}_{50}$ for the cell line LN229 was $43.11 \mu \mathrm{M} 17 \beta$-estradiol (188.01 $\mu \mathrm{M}$ for solvent control) and for LN18: $20.96 \mu \mathrm{M}$ 17 $\beta$-estradiol (solvent control: $-191.14 \mu \mathrm{M}$ ). After $17 \beta$-estradiol and chemotherapy significantly lower cell viability, i.e. stronger sensitivity against TMZ, was seen for the estradiol concentrations $25 \mu \mathrm{M}$ and $50 \mu \mathrm{M}$ for both cell lines (Figs. 5b and 5c).

\section{Discussion}

GBM still has an unfavorable prognosis, despite combined therapy. Interestingly, higher incidence rates can be observed for male patients. Moreover, animal studies have shown that GBM tumor growth is sex specific $[11,12]$. The neurobiological reason for this gender difference remains unclear, and it seems obvious that sexual hormones, like estrogen, may play a key role in the development and tumor proliferation. Since estrogen binds to ERs it is possible that the amount of ERs could be a survival factor for men and women.

To further elucidate this hypothesis we analyzed the expression of sexual hormone receptor $\mathrm{ER} \alpha$ and the hormone converting enzyme aromatase in male and female GBM patients, in relation to patients' survival times. By immunohistochemistry we were able to show that high expression of $\mathrm{ER} \alpha$ and aromatase was associated with longer patient survival, gender independently. On the basis of these results we investigated the direct effect of estradiol in combination to $\mathrm{TMZ}$ on glioblastoma tumor cells in vitro. We were able to show that estrogen treatment decreased tumor cell viability and increased the sensitivity to TMZ.

Our cohort consists of 60 GBM patients with a similar amount of men (31) and women (29). The median age of both groups is also similar (female: 60 years, male: 58 years), suggesting high comparability of the groups. All patients received a cross total resection followed by adjuvant

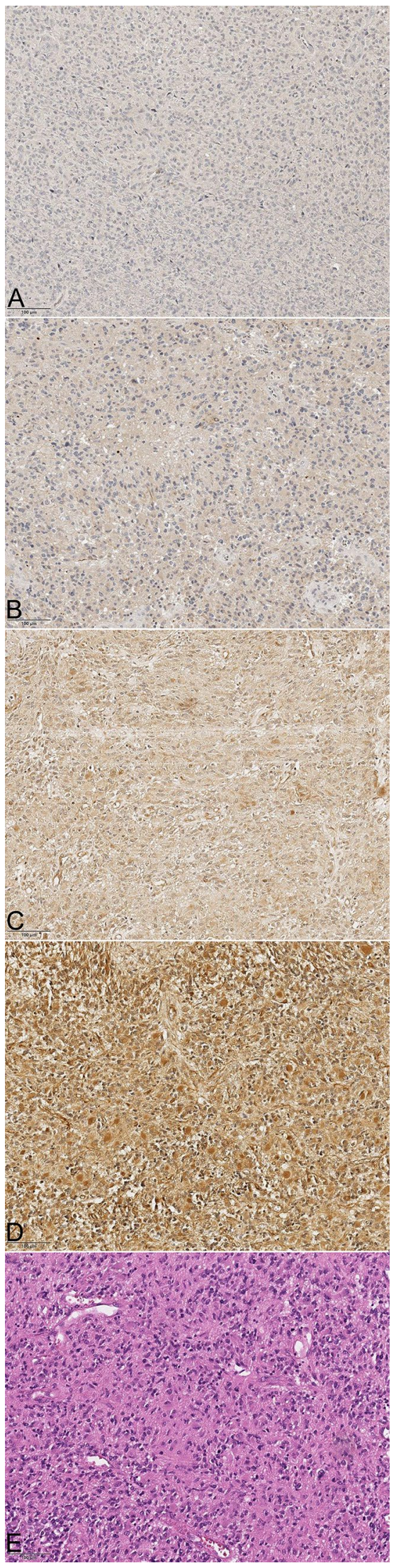



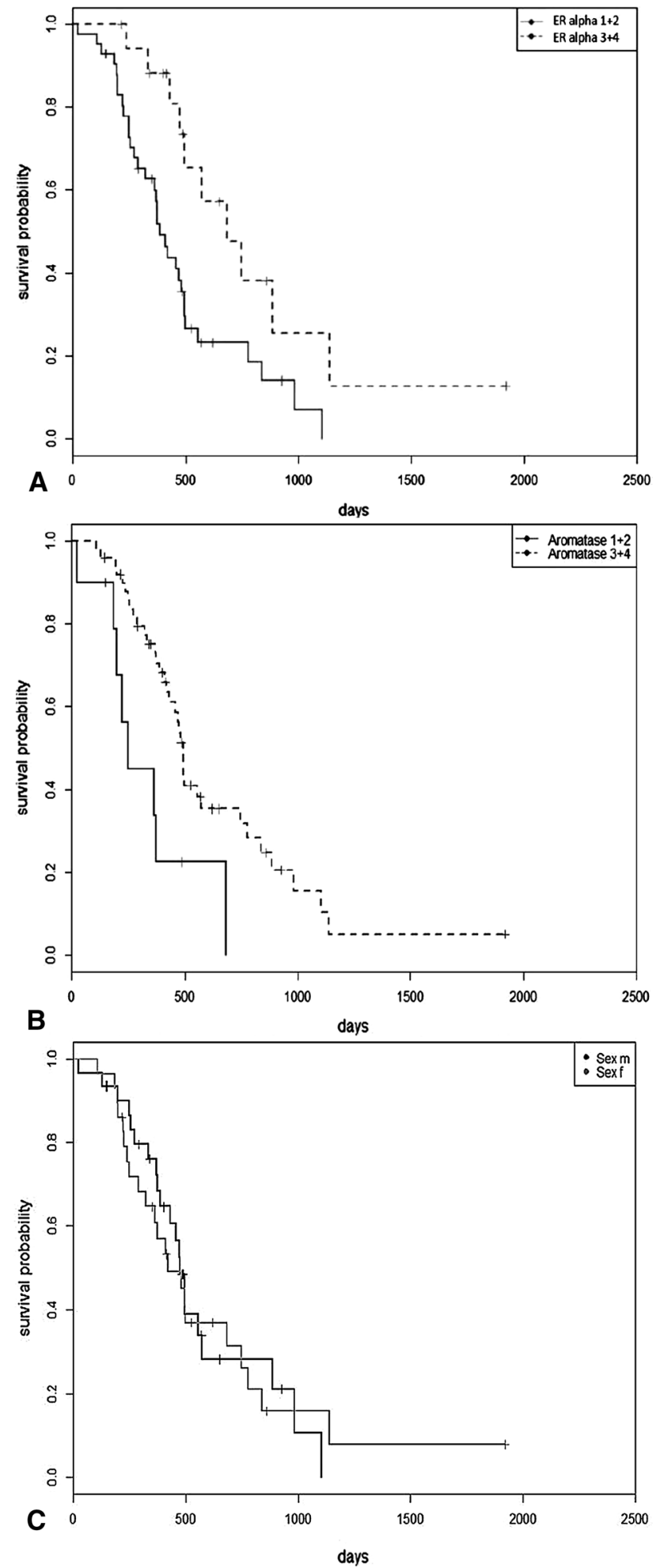

Fig. 3 Kaplan-Meier survival curves for glioblastoma patients and the expression of ER $\alpha$ and aromatase. a High expression of ER $\alpha$ (dashed line, assessment group 3 and 4) was associated with significantly longer survival ( $p=0.011$ ), compared to low expression (continuous line, assessment group 1 and 2). b Significantly longer survival $(p=0.0104)$ for glioblastoma patients with high aromatase expression (dashed line, assessment group 3 and 4), compared to low enzyme expression. c Survival analysis for male (m) and female (f) GBM patients showed no difference between the groups $(\mathrm{p}>0.89)$

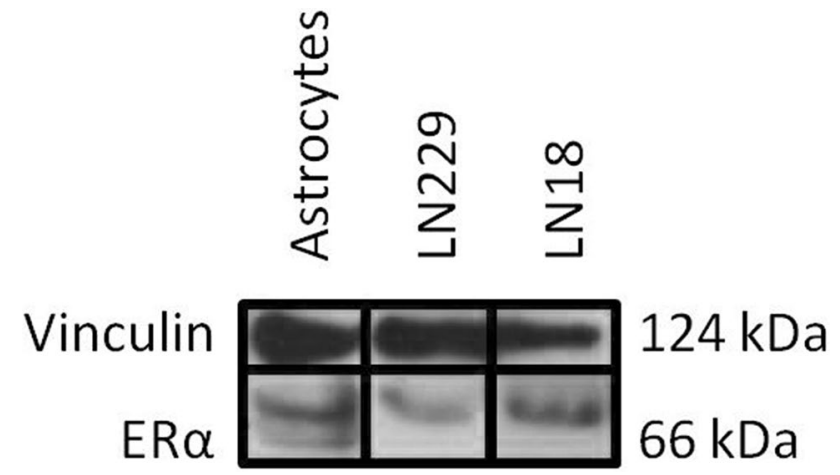

Fig. 4 Western blot analysis of the cell lines LN229 and LN18. Vinculin was used as housekeeping gene. Both cell lines showed a distinct band for estrogen receptor alpha $(\mathrm{ER} \alpha, 66 \mathrm{kDa}$, Western blot optical density for ER $\alpha$ : LN229: 1.16, LN18: 0.67). Primary astrocytes were used as positive control (Western blot optical density for $\mathrm{ER} \alpha 0.74)$

radiation and chemotherapy. The patients had a Karnofsky index greater than $60 \%$. Further information regarding individual drug intake was not known for our cohort.

Whereas previous studies commonly focused on ERs or hormone converting enzymes [24, 25], we performed immunohistochemistry for both: ER $\alpha$ and aromatase. Selective estrogen receptor inhibitors, as well as Selective Estrogen Receptor Modulators, inhibit the growth of gliomas and induce apoptosis [26-29], indicating that estrogen modulates the tumor growth via the classical nuclear estrogen receptors. The synthesis, regulation and also the effect of estradiol is not only influenced by glial tumor cells but also by the microenvironment, particularly by reactive astrocytes. These cells that surround the tumor margins are another source for estradiol and express ERs and aromatase [15]. Although we investigated the vital core region of the tumor and therefore evaluated the regions of highest tumor cell content, definite distinction between reactive astrocytes and tumor cells is not always possible morphologically. Since glial tumors have a truly diffusely infiltrating growth pattern within the brain, to date only IDH1/IDH2-mutated glioma cells can be sharply distinguished form reactive glia, using immunostaining. In this study, we examined only IDH1/IDH2-wildtype GBMs.

From epidemiological studies we know that the incidence of GBM is 1.6-2.0 times higher in men than in women [4]. This effect was especially pronounced between groups of pre-menopausal women compared to a male cohort. This gender advantage disappears in post-menopausal women [19]. However, our GBM patient cohort showed genderindependent survival times. One reason for this effect could be that the cohort was more homogeneous with mainly postmenopausal women (median age 60).

Jimenez et al. analysed different types of glial tumors and showed that estrogen concentrations were highest in 

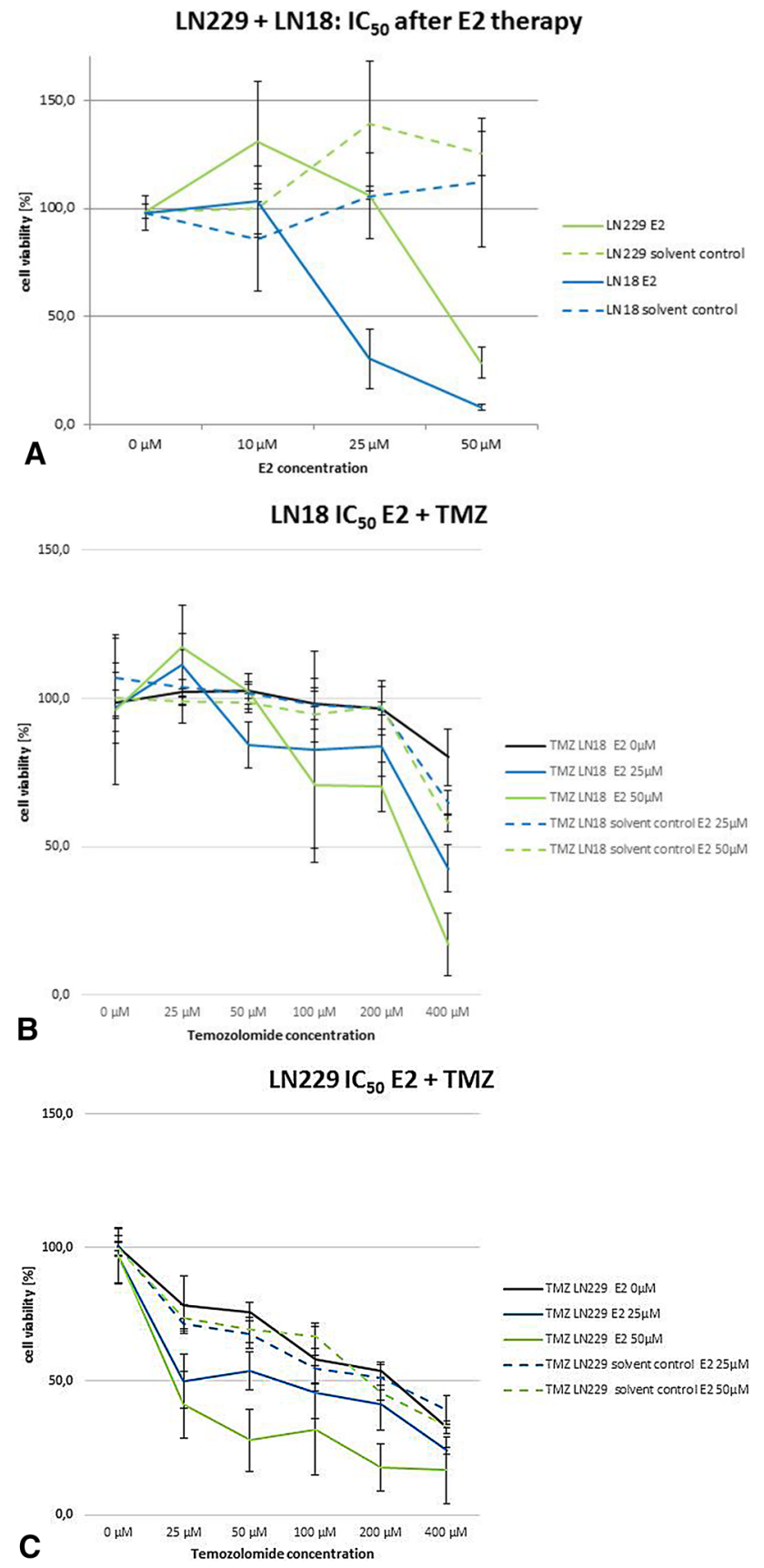

Fig. 5 a $\mathrm{IC}_{50}$ calculation for LN229 (green) and LN18 (blue) after the therapy with $10 \mu \mathrm{M}, 25 \mu \mathrm{M}$ and $50 \mu \mathrm{M} 17 \beta$-estradiol (E2). For LN229 cells a significantly lower cell viability was seen for $50 \mu \mathrm{M}$ E2 $\left(\mathrm{IC}_{50}=43.11 \mu \mathrm{M}\right)$. Despite LN18 cells showed an $\mathrm{IC}_{50}$ of $20.96 \mu \mathrm{M}$ E2. b IC $\mathrm{IC}_{50}$ calculation for LN18 after the therapy with $17 \beta$-estradiol (E2) and TMZ in different dosing regimens. The cells with the pretreatment of $25 \mu \mathrm{M}$ and $50 \mu \mathrm{M}$ E2 showed a significantly lower cell viability compared to the control. The treatment with $10 \mu \mathrm{M}$ E2 (not shown in the diagram) was equal to the control. $\mathbf{c} \mathrm{IC}_{50}$ calculation for LN229 after the therapy with E2 and TMZ in different dosing regimens. The cells with the pre-treatment of $25 \mu \mathrm{M}$ and $50 \mu \mathrm{M}$ E2 showed a significantly lower cell viability compared to the control. The treatment with $10 \mu \mathrm{M}$ E2 (not shown in the diagram) was equal to the control
GBM biopsies compared to low grade astrocytomas and were directly related to high aromatase expression [30]. In addition, they showed that the mRNA expression of ER $\alpha$ was higher than the expression of ER $\beta$ and the immunoreactivity of aromatase and estrogen receptors decreased with higher grades of tumor malignity. They also reported that patients with low ER $\alpha$ were associated with the worst prognosis, which is concordant with our findings. In their study mRNA levels of aromatase were inversely correlated to the survival time. In our study, we investigated aromatase protein levels in a homogeneous IDH1-wildetype GBM cohort, whereas Jimenez et al. analysed different glial tumors of different biological background and grades of malignity. In addition, it should be noted that measuring mRNA-levels in a tumor lysate is a different approach to studying immunohistochemical expression in individual cells within a tissue.

In breast cancer, high dose estrogen therapy $(5-100 \mu \mathrm{M})$ on ER positive breast cancer cells leads to inhibition of tumor proliferation and increases the percentage of S-, G2and M-phase, by decreasing the percentage of G0 and G1 cells [31]. In our study the glioma cell lines were treated with a high dosage of $17 \beta$-estradiol $(10 \mu \mathrm{M}, 25 \mu \mathrm{M}, 50 \mu \mathrm{M})$ over $48 \mathrm{~h}$ as a pretreatment before chemotherapy. TMZ was given over 5 days, similar to one cycle in clinical treatment. The TMZ dosage was based on the calculated $\mathrm{IC}_{50}$ dosages for the cell lines LN18 and LN229 [32]. As expected, the pretreated cells showed a higher sensitivity against TMZ, compared to control.

Estrogen interacts with the nuclear ER $\alpha$ and $\beta$ but the distinct functions of these receptor types are still unclear. $E R \alpha$ knockout mice suffered from more pronounced brain tissue damage after induced hypoxia compared to ER $\beta$ knockout mice that showed no difference to the untreated control group [20]. This supports our finding that ER $\alpha$ plays an important role in tumor suppression and represents an important survival factor.

As anticipated, the therapy with estradiol, in a dose depending manner, resulted in a slower tumor growth rate of LN18 and LN229 [24]. While low dose treatment (10 $\mu \mathrm{M}$ estradiol) was equal to the control, higher concentrations led to a decrease in cell viability.

To the authors knowledge this is the first experimental study of a combined $17 \beta$-estradiol and chemotherapy treatment on glioblastoma cell lines. Diverse studies with 2ME2 (metabolite of estrogen) therapy in combination to radiation [33], as well as selective ER $\beta$ agonist combined with chemotherapy [26, 34] or selective estrogen receptor modulators with TMZ and radiation [28], showed a sensitization against chemotherapy or radiation and a decrease in cell viability. After estradiol pre-treatment a sensitization against TMZ was seen. However, it is difficult to distinguish which ER subtype is responsible for this effect. Further studies are 
necessary to get a deeper insight in the molecular mechanisms of ER subtypes.

Despite the neuroprotective effects of estradiol in the brain, it leads to many unwanted side effects like feminization in men, increased risk of cardiovascular disease, thrombosis and different types of cancer, especially invasive breast cancer [35]. More knowledge will be essential to design special targeted therapy with lower risks for side effects.

\section{Conclusion}

High expression of $E R \alpha$ and aromatase showed an advantage in GBM patients' survival. In vitro therapy with estradiol demonstrated stemming effects on tumor progression. The administration of estradiol before conventional postoperative chemotherapy and radiation may be beneficial to glioblastoma patients and will have to be examined in further studies and clinical trials.

Acknowledgements Open Access funding provided by Projekt DEAL.

\section{Compliance with ethical standards}

Conflict of interest The authors have no financial or nonfinancial conflicts of interest to disclose.

Ethical approval All procedures performed in studies involving human participants were in accordance with the ethical standards of the local ethics committee (Klinikum rechts der Isar, UE 087-13) and with the 1964 Helsinki declaration and its later amendments or comparable ethical standards. The specimens for this retrospective study were collected at the neurosurgery department of Klinikum rechts der Isar, Technische Universität München (TUM) with patients'consent according to the TUM medical faculty's guidelines for tissue preservation. All patients had signed informed consent dorms according to the local ethics committee. Tissue samples for histopathological diagnosis and molecular genetic analysis were acquired during tumour resection at the NeuroKopf-Zentrum, Klinikum rechts der Isar, TUM. Tumour diagnoses of glioblastoma multiforme, WHO IV, were established by two independent neuropathologists at Institute für Allgemeine Pathologie und Pathologische Anatomie der TUM.

Open Access This article is licensed under a Creative Commons Attribution 4.0 International License, which permits use, sharing, adaptation, distribution and reproduction in any medium or format, as long as you give appropriate credit to the original author(s) and the source, provide a link to the Creative Commons licence, and indicate if changes were made. The images or other third party material in this article are included in the article's Creative Commons licence, unless indicated otherwise in a credit line to the material. If material is not included in the article's Creative Commons licence and your intended use is not permitted by statutory regulation or exceeds the permitted use, you will need to obtain permission directly from the copyright holder. To view a copy of this licence, visit http://creativecommons.org/licenses/by/4.0/.

\section{References}

1. Louis DN et al (2016) The 2016 World Health Organization classification of tumors of the central nervous system: a summary. Acta Neuropathol 131(6):803-820

2. Stupp R et al (2005) Radiotherapy plus concomitant and adjuvant temozolomide for glioblastoma. N Engl J Med 352(10):987-996

3. Stupp R et al (2015) Maintenance therapy with tumor-treating fields plus temozolomide vs temozolomide alone for glioblastoma: a randomized clinical trial. JAMA 314(23):2535-2543

4. Ostrom QT et al (2015) CBTRUS statistical report: primary brain and central nervous system tumors diagnosed in the United States in 2008-2012. Neuro Oncol 17(Suppl 4):iv1-iv62

5. Herson PS, Koerner IP, Hurn PD (2009) Sex, sex steroids, and brain injury. Semin Reprod Med 27(3):229-239

6. Wang C, Jie C, Dai X (2014) Possible roles of astrocytes in estrogen neuroprotection during cerebral ischemia. Rev Neurosci 25(2):255-268

7. Kipp M et al (2016) Female sex steroids and glia cells: Impact on multiple sclerosis lesion formation and fine tuning of the local neurodegenerative cellular network. Neurosci Biobehav Rev 67:125-136

8. Bramlett HM, Dietrich WD (2001) Neuropathological protection after traumatic brain injury in intact female rats versus males or ovariectomized females. J Neurotrauma 18(9):891-900

9. McCullough LD et al (2003) Aromatase cytochrome P450 and extragonadal estrogen play a role in ischemic neuroprotection. J Neurosci 23(25):8701-8705

10. Spence RD et al (2011) Neuroprotection mediated through estrogen receptor-alpha in astrocytes. Proc Natl Acad Sci USA 108(21):8867-8872

11. Verzat $C$ et al (1990) Influence of host sex on the growth of a human glioblastoma line in athymic mice. Neuropathol Appl Neurobiol 16(2):141-151

12. Plunkett RJ et al (1999) Hormonal effects on glioblastoma multiforme in the nude rat model. J Neurosurg 90(6):1072-1077

13. Boon WC, Chow JDY, Simpson ER (2010) The multiple roles of estrogens and the enzyme aromatase. Prog Brain Res 181:209-232

14. Azcoitia I, Yague JG, Garcia-Segura LM (2011) Estradiol synthesis within the human brain. Neuroscience 191:139-147

15. Acaz-Fonseca E et al (2016) Regulation of astroglia by gonadal steroid hormones under physiological and pathological conditions. Prog Neurobiol 144:5-26

16. Roselli CE, Liu M, Hurn PD (2009) Brain aromatization: classic roles and new perspectives. Semin Reprod Med 27(3):207-217

17. Caruso D et al (2013) Comparison of plasma and cerebrospinal fluid levels of neuroactive steroids with their brain, spinal cord and peripheral nerve levels in male and female rats. Psychoneuroendocrinology 38(10):2278-2290

18. Caruso D et al (2010) Effect of short-and long-term gonadectomy on neuroactive steroid levels in the central and peripheral nervous system of male and female rats. J Neuroendocrinol 22(11):1137-1147

19. Kabat GC, Etgen AM, Rohan TE (2010) Do steroid hormones play a role in the etiology of glioma? Cancer Epidemiol Biomark Prev 19(10):2421-2427

20. Dubal DB et al (2006) Differential modulation of estrogen receptors (ERs) in ischemic brain injury: a role for ERalpha in estradiol-mediated protection against delayed cell death. Endocrinology 147(6):3076-3084

21. Dubal DB et al (2001) Estrogen receptor alpha, not beta, is a critical link in estradiol-mediated protection against brain injury. Proc Natl Acad Sci USA 98(4):1952-1957

22. Heldring $\mathrm{N}$ et al (2007) Estrogen receptors: how do they signal and what are their targets. Physiol Rev 87(3):905-931 
23. McShane LM et al (2005) Reporting recommendations for tumour MARKer prognostic studies (REMARK). Eur J Cancer 41(12):1690-1696

24. Barone TA et al (2009) Estrogen increases survival in an orthotopic model of glioblastoma. J Neurooncol 95(1):37-48

25. Yague JG et al (2004) Aromatase, the enzyme responsible for estrogen biosynthesis, is expressed by human and rat glioblastomas. Neurosci Lett 368(3):279-284

26. Sareddy GR et al (2016) Selective estrogen receptor $\beta$ agonist LY500307 as a novel therapeutic agent for glioblastoma. Sci Rep 6:24185

27. Sareddy GR et al (2012) Therapeutic significance of estrogen receptor beta agonists in gliomas. Mol Cancer Ther 11(5):1174-1182

28. Baritchii A et al (2016) Sensitizer drugs for the treatment of temozolomide-resistant glioblastoma. J Buon 21(1):199-207

29. Balca-Silva J et al (2015) Tamoxifen in combination with temozolomide induce a synergistic inhibition of PKC-pan in GBM cell lines. Biochim Biophys Acta 1850(4):722-732

30. Duenas Jimenez JM et al (2014) Aromatase and estrogen receptor alpha mRNA expression as prognostic biomarkers in patients with astrocytomas. J Neurooncol 119(2):275-284

31. Reddel RR, Sutherland RL (1987) Effects of pharmacological concentrations of estrogens on proliferation and cell cycle kinetics of human breast cancer cell lines in vitro. Cancer Res 47(20):5323-5329

32. Happold C et al (2012) Distinct molecular mechanisms of acquired resistance to temozolomide in glioblastoma cells. J Neurochem 122(2):444-455

33. Eyvazzadeh $\mathrm{N}$ et al (2015) Genotoxic damage to glioblastoma cells treated with $6 \mathrm{MV} \mathrm{X}$-radiation in the presence or absence of methoxy estradiol, IUDR or topotecan. Cell J 17(2):312-321

34. Liu $X$ et al (2015) Estrogen receptor beta agonist enhances temozolomide sensitivity of glioma cells by inhibiting PI3K/AKT/ mTOR pathway. Mol Med Rep 11(2):1516-1522

35. Rossouw JE et al (2002) Risks and benefits of estrogen plus progestin in healthy postmenopausal women: principal results From the Women's Health Initiative randomized controlled trial. JAMA 288(3):321-333

Publisher's Note Springer Nature remains neutral with regard to jurisdictional claims in published maps and institutional affiliations. 